\title{
INTERPRETAÇÃO CONSTITUCIONAL: LEGITIMIDADE DEMOCRÁTICA DA JURISDIÇÃO CONSTITUCIONAL, DIFICULDADE CONTRAMAJORITÁRIA DO PODER JUDICIÁRIO E INTERPRETAÇÃO INCONSTITUCIONAL \\ CONSTITUTIONAL INTERPRETATION: DEMOCRATIC LEGITIMACY OF CONSTITUTIONAL JURISDICTION, THE COUNTER-MAJORITARIAN DIFFICULTY IN THE JUDICIARY POWER, AND UNCONSTITUTIONAL INTERPRETATION
}

\section{Marco Vicente Dotto Köhler ${ }^{1}$}

Resumo: A presente pesquisa tem por objetivo analisar e refletir acerca da interpretação constitucional, demonstrando a fundamental importância dessa tarefa para toda a sociedade; analisar a quem cabe a interpretação, como ela ocorre e, por fim, se é possível a existência de interpretação inconstitucional (ou inconstitucionalidade na interpretação), e como ela pode ocorrer. Para melhor compreensão desses aspectos, necessário se fez tratar também da legitimidade democrática da jurisdição constitucional, da dificuldade contramajoritária do Poder Judiciário, ainda que de fora perfunctória, pois não é objeto da pesquisa, mas tão somente tema incidental, porém necessário ao melhor desenvolvimento do artigo.
Palavras-chave: Interpretação constitucional e inconstitucional. Legitimidade democrática. Dificuldade contramajoritária.

Abstract: The research provide an analyzes about interpretation under constitutional law; indeed, enlightening the core importance of this duty to all of society. It also aims to identify who is the person in charge of the interpretation, how it occurs, and finally, if it is possible to find a constitutional interpretation (or unconstitutional interpretation), and how it can occur. For a better understanding of these aspects, it has been necessary to talk about the democratic legitimacy of the constitutional jurisdiction,

1 Técnico judiciário auxiliar. Atualmente ocupa o cargo de Distribuidor judicial da comarca de Lauro Müller-SC. Pós-graduando, em nível de Especialização, pela Universidade Anhanguera-Uniderp, por meio da rede LFG, em Direito Constitucional. Aluno do Módulo I da Escola Superior da Magistratura do Estado de Santa Catarina (Esmesc), extensão de Tubarão-SC. E-mail: dottokohler@yahoo.com.br 
the counter-majoritarian difficulty of the judiciary, even thought it is perfunctory, due to the fact that it is not the object of this research, but only a linked subject of this article.
KEYWORDS: Constitutional and unconstitutional interpretation. Democratic legitimacy. Difficulty countermajoritarian

\section{INTRODUÇÃO}

$\mathrm{O}$ artigo trata da interpretação da constituição, como ela ocorre, quem são os intérpretes e se há possibilidade de interpretação inconstitucional e como pode ocorrer esse fenômeno.

Não objetiva o aprofundamento em tais matérias, muito menos tenta esgotá-las, tarefa incompatível com os temas, eis que estão em constante evolução, acompanhando as transformações da sociedade, e a forma com que se vê a Constituição e, por conseguinte, o modo de interpretá-la.

Poderia ser tratado aqui também de outros tópicos que são não apenas correlatos, mas umbilicalmente interligados entre si, como: o conflito intergeracional; a dimensão política da jurisdição constitucional, que alguns autores tratam como judicialização (ou judicização) da política ou politização da justiça; ativismo judicial; judicialização dos conflitos sociais; constitucionalização do Direito, etc.

No entanto, não cabem aqui todos eles, motivo pelo qual se focou na interpretação constitucional, com algumas imersões quanto à legitimidade democrática e dificuldade contramajoritária do poder judiciário, pois se fez necessário para a compreensão da fundamental importância da interpretação constitucional e da possibilidade de existir inconstitucionalidade na interpretação (ou interpretação inconstitucional).

Para que se possa melhor entender os temas que são aqui tratados, necessário se faz falar do conceito de Constituição, ainda que sem maior profundidade. 


\section{CONCEITO DE CONSTITUIÇÃO}

Antes de adentrar no tema do artigo, que trata precipuamente da interpretação da Constituição, importante esclarecer o que se entende por Constituição, primeiro, por ser ela o objeto central dos estudos a serem desenvolvidos no presente trabalho; segundo, por ser plurívoca a noção conceitual de Constituição. (MENDES, 2017, p. 55; BULOS, 2014, p. 100).

Para Sarmento,

A ideia de Constituição, tal como a conhecemos hoje, é produto da modernidade, sendo tributária do Iluminismo e das revoluções burguesas dos séculos XVII e XVIII, ocorridas na Inglaterra e nos Estados unidos e na França. Ela está profundamente associada ao constitucionalismo moderno, que preconiza a limitação jurídica do poder político em favor dos direitos dos governados. (SARMENTO, 2017, p. 69).

Conforme leciona Bulos, "Constituição é o organismo vivo delimitador da organização estrutural do Estado, da forma de governo, da garantia das liberdades públicas, do modo de aquisição e exercício do poder" (BULOS, 2014, p. 100, grifo do autor).

Mais adiante, explica o autor, que conceitua como organismo vivo pois quando da criação de uma constituição "[...] é incumbência do legislador prever possíveis modificações futuras [...]" (BULOS, 2014, p. 101).

Silva entende por Constituição

[...] algo que tem, como forma, um complexo de normas (escritas ou não); como conteúdo, a conduta humana motivada pelas relações sociais [...]; como fim, a realização dos valores que apontam para o existir da comunidade; e, finalmente, como causa criadora e recriadora, o poder que emana do povo. (SILVA, 2008, p. 39, grifo do autor).

$\mathrm{O}$ autor, ao conceituar Constituição, demonstra que a interpretação constitucional está, de certa forma, embutida no próprio conceito, eis que a Constituição "[...] não pode ser compreendida e interpretada, se não tiver em mente essa estrutura, 
considerada como conexão de sentido, como é tudo aquilo que integra um conjunto de valores." (SILVA, 2008, p. 39).

A Constituição pode ser conceituada sob vários prismas, podendo o seu intérprete conceituá-la de acordo com enfoque que esteja dando a seu trabalho ou argumento, pois ela pode ser interpretada, nesse sentir, sob a ótica formal ou material; ou dos direitos fundamentais, da construção histórica, ou da luta entre os poderes.

No presente trabalho, como dito, não é objetivo principal definir um conceito que se julgue como o melhor, mas apenas demonstrar que comumente fazem parte dos elementos conceituais da Constituição: documento assegurador de direitos, prerrogativas, garantias, competências, deveres e encargos; garantidor das liberdades e dos direitos fundamentais (em suas várias dimensões); um documento que defina os limites do poder e a organização do Estado e que tenha como origem a vontade do Povo, sendo a lei fundamental da sociedade. (BULOS, 2014, p. 100; MENDES, 2017, p. 55-56; SARMENTO, 2017, p. 69-70; SILVA, 2008, p. 39-40).

Por fim, pode-se afirmar que os conceitos apresentados, mais ou menos extensos e abrangentes, não encontram guarida ainda na origem latina do verbo constituere, que exterioriza "[...] a ideia de constituir, estabelecer, firmar, formar, organizar, delimitar." (BULOS, 2014, p. 100).

\section{INTERPRETAÇÃO DA CONSTITUIÇÃO}

Após a breve explanação quanto ao conceito de Constituição, parte-se para o objeto do trabalho, que é a interpretação da Constituição, sendo que a abordagem ao tema se dá tratando da importância, como se dá e a quem cabe a interpretação constitucional, bem como se há possibilidade de interpretação inconstitucional.

Para facilitar a compreensão e também para melhor estru- 
turação do texto, dividiu-se em subtítulos os diversos aspectos da interpretação, iniciando-se pela importância da interpretação.

\subsection{Importância da interpretação}

A Constituição da República, de 1988, estabelece, no caput do art. $1^{\circ}$, que "A República Federativa do Brasil, formada pela união indissolúvel dos Estados, Municípios e do Distrito Federal, constitui-se em Estado Democrático de Direito [...]" (BRASIL, 1988).

A interpretação desse dispositivo, ainda que sem maior aprofundamento, já permite vislumbrar que o Brasil respeita o princípio republicano e a forma federativa (indissolúvel) do Estado (BARROSO, 2009a, p. 171). Estado este que, além de democrático, é um Estado de Direito, o que permite dizer, portanto, que é vinculado a leis e, sobretudo, à Constituição, com a qual a legislação infraconstitucional deve ser compatível (THEODORO JUNIOR, 2009, p. 412-413).

Dessa simples análise do primeiro artigo da Lei Maior, percebe-se o quão importante é a tarefa da interpretação da Constituição, e o quanto deve ser levada a sério tal função.

Cumpre lembrar que a Constituição do Brasil, de 1988, pode ser classificada como: formal, escrita codificada, unitária, eclética, analítica, rígida, dogmática, promulgada (democrática, popular), principio lógica, social e expansiva. (BULOS, 2014, p. 118-121; MORAES, 2012, p. 11; PAULO; ALEXANDRINO, 2015, p. 33; SILVA, 2008, p. 40).

Dos elementos da classificação acima, é da "rigidez" que se extrai a consequência da supremacia da Constituição Federal, pois é por esse elemento que se tem a Constituição como "[...] lei fundamental e suprema do Estado Brasileiro." (SILVA, 2008, p. 46). Por isso que "[...] todas as normas que integram a ordenação jurídica nacional só serão válidas se se conformarem com as normas da Constituição Federal.” (SILVA, 2008, p. 46). 
Partindo desse ponto, chega-se à interpretação constitucional, e à sua extrema importância (SARMENTO, 2017, p.395), pois é por meio dela que se pode dar o sentido às palavras do texto constitucional (MORAES, 2012, p.15) e, também, verificar se as normas infraconstitucionais estão de acordo com a Constituição.

Para Mendes, "[...] a interpretação constitucional tende a acarretar impacto sobre todo o direito positivo do Estado, já que é a Constituição a norma suprema em uma comunidade e a fonte de legitimidade formal de toda a sua ordem jurídica." (MENDES, 2017, p. 79).

A Constituição como cume do ordenamento jurídico de um Estado, da forma demonstrada na pirâmide de Kelsen, encontra lastro no Estado de Direito, "[...] que emerge como uma construção própria à segunda metade do século XIX, [...], vinculado a uma percepção de hierarquia das regras jurídicas, com o objetivo de enquadrar e limitar o poder do Estado pelo Direito" (STRECK, 2003, p. 86).

No que tange ao Estado Democrático de Direito, este vai além do Estado Liberal de Direito e do Estado Social de Direito, pois impõe "[...] à ordem jurídica e à atividade estatal um conteúdo utópico de transformação da realidade." (STRECK, 2003, p. 93-94).

Por esse prisma, sendo o Estado Democrático de Direito um Estado Constitucional, "[..] a interpretação das constituições equivale ao ponto nuclear da Teoria do Estado, e, de certa maneira, da Teoria do Direito." (BULOS, 2014, p. 447).

Dessa forma, inegável a importância da interpretação constitucional, não apenas para o ordenamento jurídico em si, mas para toda a sociedade, para o Estado Democrático de Direito.

\subsection{Como se dá a interpretação constitucional}

No presente trabalho, no entanto, não é esse viés da interpretação constitucional que se quer analisar, de verificação 
de inconstitucionalidades de leis e atos normativos perante a Constituição, que é bem estudada no que tange ao controle de constitucionalidade.

O que se busca é expor como se dá o processo de interpretação da Constituição, de como se atribui sentido e significação ao texto constitucional em si e quem é (ou quem são) o(s) intérprete(s).

Primeiramente, e de fundamental importância, compreendermos a interpretação constitucional, haja vista que dela advêm importantes consequências para todos nós, enquanto povo, enquanto sociedade e enquanto Estado.

Tanto é assim que Mendes afirma que a busca por um sentido às normas tem por objetivo a "[...] conformação social [e é a interpretação constitucional], atividade marcada por considerável potencial de efeitos vários sobre a ordem jurídica e sobre o quotidiano dos indivíduos." (MENDES, 2017, p. 79).

Bulos assevera que a interpretação constitucional é o "[...] coração dos debates constitucionais [...]", e, por isso, é “[...] um dos maiores desafios colocados para o aplicador do Direito e um dos campos mais fecundos e prioritários do labor científico dos juristas." (BULOS, 2014, p. 447).

Para Canotilho, "interpretar uma norma constitucional consiste em atribuir um significado a um ou vários símbolos linguísticos escritos na constituição com o fim de obter uma decisão de problemas práticos normativo-constitucionalmente fundada". (CANOTILHO, 2003, p. 1200).

$\mathrm{O}$ autor português sugere, ainda, três dimensões importantes da constituição:

[...] (1) Interpretar a Constituição significa procurar o direito contido nas normas constitucionais; (2) investigar o direito contido na lei constitucional implica uma atividade - atividade complexa - que se traduz fundamentalmente na $<<$ adscrição $>>$ de um significado a um enunciado ou disposição linguística ("texto da norma"); (3) o produto 
do acto de interpretar é o significado atribuído. (CANOTILHO, 2003, p. 1200-1201).

Tem-se, dessa forma, que "interpretar as normas constitucionais significa (como toda a interpretação de normas jurídicas) compreender, investigar e mediatizar o conteúdo semântico dos enunciados linguísticos que formam o texto constitucional”. (CANOTILHO, 2003, p. 1206).

Não existe um caminho único para interpretar a constituição, existindo, no entanto, métodos de interpretação constitucional.

Dos mais usuais, tem-se os seguintes (BULOS, 2014, p. 454):

a. métodos clássicos, que se utilizam os critérios gramatical, lógico, histórico, sistemático, teleológico, popular, doutrinário e evolutivo;

b. métodos modernos, com os critérios tópico-problemático, hermenêutico-concretizador, científico-espiritual, normativo estruturante e o de comparação constitucional;

c. princípios interpretativos: unidade da constituição, correção funcional, concordância prática (ou harmonização), eficácia integradora (ou efeito integrador), força normativa da constituição, máxima efetividade, razoabilidade (ou proporcionalidade); princípio da conformidade (ou da justeza constitucional), que pode ser subdividido em: prevalência da Constituição; conservação de normas; e exclusão de interpretação contra legem;

d. técnicas de interpretação: ponderação de valores (ou interesses), otimização de princípios, e filtragem constitucional.

Pelo exposto, vê-se que é complexa a interpretação constitucional, sendo "[...] propensa a controvérsias, que se estendem desde as técnicas que lhe são adequadas até os limites a que se deve ater [...]" (MENDES, 2017, p. 82), não cabendo, portanto, nestas páginas, aprofundamentos sobre 
os meios de interpretação.

Não é objetivo do presente trabalho, esmiuçar tais métodos, técnicas e princípios interpretativos, mas tão somente buscar demonstrar que não existe uma forma única de interpretação constitucional, pois “"...] todos os métodos, meios, técnicas, processos, princípios e regras de exegese, até hoje elaborados, conduzem sempre a um resultado apenas possível, mas não o único correto." (BULOS, 2014, p. 453).

Dos elementos acima, para os objetivos buscados no presente artigo, dá-se mais atenção ao gramatical e aos limites textuais para atividade do intérprete, pois deles decorrem os questionamentos mais adiante desenvolvidos, sobre a possibilidade, ou não, de interpretação inconstitucional.

\subsection{A quem cabe a interpretação constitucional}

Do próprio texto constitucional pode-se extrair um indicativo de ao menos um dos intérpretes possíveis: Ao Supremo Tribunal Federal cabe, como função precípua, a guarda da Constituição (CRFB/88, art. 102, caput).

Não há dúvidas quanto à competência do Supremo Tribunal Federal, como Corte Constitucional, cabendo somente a esta o controle concentrado de constitucionalidade (MORAES, 2012, p. 574).

No entanto, mesmo que caiba ao STF o controle concentrado, e que seja sua a função precípua de guarda da Constituição, é dizer que somente ao STF cabe tal função? Seria dizer que ser guardião é sinônimo de ser o intérprete final, devendo ser da Suprema Corte a palavra final?

Da própria supremacia da Constituição, pedra fundamental do Estado Democrático de Direito, bem como por ser rígida a nossa Lei Maior, como visto, decorre que "toda autoridade só nela encontra fundamento e só ela confere poderes e competências governamentais". (SILVA, 2008. p. 46). 
Interpretar a constituição, portanto, "[...] é uma tarefa que se impõe metodicamente a todos os aplicadores das normas constitucionais (legislador, administração, tribunais)." (CANOTILHO, 2003, p. 1207).

Häberle, por sua vez, propõe a seguinte tese:

no processo de interpretação constitucional estão potencialmente vinculadas todos os órgãos estatais, todas as potências públicas, todos os cidadãos e grupos, não sendo possível estabelecer-se um elenco cerrado ou fixado com numerus clausus de intérpretes da Constituição. (HÄBERLE, 2014, p. 27).

Mais adiante, afirma que, ainda que a última palavra na interpretação possa ser dada em controle concentrado, "Como não são apenas os intérpretes jurídicos da Constituição que vivem a norma, não detêm eles o monopólio da interpretação da Constituição." (HÄBERLE, 2014, p. 28).

No mesmo sentido, Sarmento (2017, p. 395-396) trata a questão da interpretação como sendo fenômeno não exclusivamente jurídico, porque "[...] não é domínio exclusivo dos juristas, nem, muito menos, dos juízes" eis que a "interpretação constitucional é uma atividade essencialmente prática e as questões com que se defronta são muitas vezes as mais importantes, complexas e controvertidas de uma Nação."

Assim, é patente que a interpretação constitucional não é exclusividade do Supremo Tribunal Federal, nem mesmo do Poder Judiciário, sendo todos que "[...] vivem sob a égide de uma carta magna, são os seus legítimos intérpretes". (BULOS, 2014, p. 448).

E com relação à palavra final em interpretação constitucional, caso exista, caberia ao Supremo emiti-la?

Da jurisprudência do próprio STF extrai-se o seguinte trecho:

A interpretação constitucional derivada das decisões proferidas pelo Supremo Tribunal Federal - a quem se atribui a função eminente de "guarda da Constituição" (CRFB/88, 
art. 102, caput) - assume papel de essencial importância na organização institucional do Estado brasileiro, a justificar o reconhecimento de que o modelo político-jurídico vigente em nosso País confere, à Suprema Corte, a singular prerrogativa de dispor do monopólio da última palavra em tema de exegese das normas inscritas no texto da Lei Fundamental (STF, ADI 4.345/DF, Pleno, rel. Min. Celso de Mello, DJe, 164/2010, p. 41-42). (BRASIL, 2010).

No mesmo sentido, Oliveira aduz que a expressão "guardião da Constituição" daria aos ministros do Supremo a "máxima função de dar estabilidade à nação", pois entende que o Judiciário, por meio do STF, seria o Poder que traria estabilidade às instituições, por meio da segurança jurídica possibilitada pela guarda da Constituição (OLIVEIRA, 2013, p. 1094).

Citando Ives Gandra da Silva Martins, Oliveira defende que “[...] o Supremo Tribunal Federal, como guardião da Constituição, é aquele que oferta a interpretação última, definitiva, que orienta, sinaliza, mostra a todos os cidadãos o caminho correto a seguir". (MARTINS apud OLIVEIRA, 2013, p. 1094).

Bulos analisa a questão da última palavra defendendo que é o Supremo Tribunal Federal quem profere a palavra final na interpretação constitucional, mas que essa palavra é, ou pode ser, influenciada pelos copartícipes do processo exegético, eis que nas pré-interpretações, nas interpretações indiretas e, notadamente nas questões de maior relevância, há uma grande participação no debate dos temas, como se deu, por exemplo, com o impeachment, com a interrupção da gravidez de anencéfalos, a contribuição de inativos, o crime de racismo etc. (BULOS, 2014, p.448).

Sarmento entende que o STF deve ser obedecido sem objeções e teimosia quando profere decisão definitiva declarando a inconstitucionalidade de ato normativo, sendo da Suprema Corte a última palavra, pois a resolução definitiva de conflitos intersubjetivos traz segurança jurídica e paz social. (SAR- 
MENTO, 2017, p. 408).

No entanto, ainda de acordo com Sarmento, pode existir o que ele chama de "[...] interação institucional na interpretação constitucional [...]" (SARMENTO, 2017, p. 410), que seria a possibilidade de edição de lei similar a outra que tenha sido julgada inconstitucional, ou até mesmo de emendas constitucionais. Estas, no entanto, devem respeitar os limites materiais impostos pelas cláusulas pétreas (art. $60, \S 4^{\circ}$, da CRFB/88), sendo que essa observância pode ser fiscalizada pela jurisdição constitucional. (SARMENTO, 2017, p. 409).

Percebe-se, portanto, que "[...] há diversos mecanismos de reação contra decisões dos Tribunais Constitucionais, que vão da aprovação de emenda constitucional em sentido contrário, à mobilização em favor da nomeação de novos ministros com visão diferente sobre o tema”. (SARMENTO, 2017, p. 405).

Por fim, Sarmento conclui que ainda que haja retórica sobre a "supremacia judicial" na interpretação constitucional, é possível se constatar na própria "jurisprudência do STF alguma abertura para revisão dos seus posicionamentos anteriores, quando postos em xeque por atos legislativos subsequentes" e que essa abertura é importante tanto para o controle recíproco dos poderes do Estado, quanto para viabilizar "[...] a correção de erros na hermenêutica constitucional". (SARMENTO, 2017, p. 413).

Pelo exposto, pode-se perceber que é consenso que a interpretação constitucional não é exclusividade do Poder Judiciário e do STF, mas sim de toda sociedade e de todos os Poderes, mas que com relação à última palavra em matéria de interpretação constitucional, o tema é claudicante, pois há possibilidade de embate entre os Poderes, o que é saudável ao Estado Democrático de Direito, pois permite que o texto constitucional possa ser interpretado de forma evolutiva, acompanhando as mudanças ocorridas na sociedade a que se vincula determinada Constituição. 


\subsection{Possibilidade de interpretação inconstitucional}

Para analisar se pode haver interpretação inconstitucional no âmbito da jurisdição constitucional, necessário tratar, ainda que de forma breve, da legitimidade democrática e da questão da dificuldade contramajoritária do Poder Judiciário.

Para isso, deve-se compreender que o poder na democracia brasileira é exercido pelo povo, indiretamente por meio de seus representantes eleitos, ocupantes dos cargos representativos dos Poderes Legislativo e Executivo federais, municipais e estaduais, e, diretamente, por meio de mecanismos de participação direta, tais como plebiscito, referendo e projeto de lei de iniciativa popular (art. 14 da CRFB/88).

No Estado brasileiro o poder, ou função (BASTOS, 1997, p. 340), é exercido de maneira "tripartida", conforme estabelece o art. $2^{\circ}$ da CRFB/88: "São Poderes da União, independentes e harmônicos entre si, o Legislativo, o Executivo e o Judiciário", tendo, cada um deles, uma atribuição típica, sendo legislar atribuição típica do Legislativo, administrar atribuição típica do Executivo, e julgar atribuição típica do Judiciário.

Além dessas funções precípuas, há outras, que lhes são atribuídas em uma tentativa de equilíbrio do poder, como no conhecido conceito de freios e contrapesos da teoria de Montesquieu, em seu $O$ Espírito das Leis.

Exemplo disso é a função de fiscalização do Executivo pelo Legislativo, de aprovação de orçamento do Judiciário pelo Executivo e do controle de constitucionalidade do Legislativo pelo Judiciário.

Assim, tem-se que o Supremo Tribunal Federal, composto por onze ministros (art. 101 da CRFB/88), com função precípua de guardião da Constituição (art. 102 da CRFB/88), acaba por determinar o sentido do que é constitucional por meio do controle da constitucionalidade, tendo, por conseguinte, na visão convencional, a última palavra sobre o que significa a 
Constituição (SARMENTO, 2017, p. 408).

Nesse cenário surge a dificuldade contramajoritária do Poder Judiciário,

“[...] que decorre do fato de os juízes, apesar de não serem eleitos, poderem invalidar as decisões adotadas pelo legislador escolhido pelo povo, invocando, muitas vezes, normas constitucionais de caráter aberto, que são objeto de leituras divergentes na sociedade.” (SARMENTO, 2017, p. 35).

Superada a questão da legitimidade democrática do Poder Judiciário, que vem inscrita no próprio texto constitucional, no já citado art. 102 da CRFB/88, e mencionada a questão da dificuldade contramajoritária, parte-se agora para o tema do presente tópico, que é saber se, na jurisdição constitucional, pode haver interpretação inconstitucional.

Como visto, todos esses pontos estão conectados, interligados por um elemento comum, que é o Supremo Tribunal Federal, motivo pelo qual a perspectiva de interpretação inconstitucional será analisada pelo prisma da interpretação existente na função precípua do STF.

Uma das consequências que podem advir da interpretação constitucional é a mutação constitucional, que ocorre quando há alteração informal da Constituição, com alteração da interpretação em controle difuso de constitucionalidade, ou seja: o sentido dado a uma determinada norma constitucional muda, sem que se altere formalmente o seu texto.

Acerca da mutação constitucional ocorrerem em controle difuso de constitucionalidade, "vale observar que as mutações constitucionais possuem as mesmas características do poder constituinte difuso, porquanto dele derivam. Logo, são latentes, permanentes, informais e contínuas". (BULOS, 2014, p. 435, grifo do autor).

Assim, vê-se claramente a conexão entre interpretar a Constituição, o Supremo Tribunal Federal, a legitimidade de- 
mocrática do Poder Judiciário e a dificuldade contramajoritária que aí existe, pois há uma alteração da Constituição, mas sem emendas constitucionais, que seria a forma de alteração formal, por meio dos representantes do povo, legitimados pelo voto (Legislativo).

Ocorre a alteração informal, pelo STF, que é composto por 11 Ministros que não são eleitos, indicados pelo Presidente da República, representante maior do Poder Executivo, que nomeará o Ministro após aprovada a escolha pela maioria absoluta do Senado Federal (art. 101, caput e parágrafo único, da $\mathrm{CRFB} / 88$ ). Aqui nota-se novamente o equilíbrio dos poderes, por meio do sistema de freios e contrapesos.

Com relação à mutação constitucional, para Mendes:

[...] a Constituição muda, sem que as suas palavras hajam sofrido modificação alguma. O texto é o mesmo, mas o sentido que lhe é atribuído é outro. Como a norma não se confunde com o texto, repara-se, aí uma mudança da norma, mantido o texto. Quando isso ocorre no âmbito constitucional, fala-se em mutação constitucional. (MENDES, 2017, p. 132).

No entanto, como visto, a interpretação é a atribuição de sentido às palavras do texto, devendo, outrossim, a nova interpretação "[...] encontrar apoio no teor das palavras empregadas pelo constituinte e não deve violentar os princípios estruturantes da Lei Maior; do contrário, haverá apenas uma interpretação inconstitucional”. (MENDES, 2017, p. 132).

Para Bulos,

[...] o fenômeno pelo qual os textos constitucionais são alterados sem revisões ou emendas denomina-se mutação constitucional. Mutação constitucional, portanto, é o processo informal de mudança das constituições que atribui novos sentidos aos seus preceitos significados e conteúdos dantes não contemplados. (BULOS, 2014, p.435).

Para melhor compreensão do fenômeno da mutação consti- 
tucional, e as divergências existentes acerca do tema, passa-se a analisar o que ocorreu com $\mathrm{O}$ art. 52, $\mathrm{X}$ da $\mathrm{CRFB} / 88$, que tem a seguinte redação:

Art. 52. Compete privativamente ao Senado Federal:

$[\ldots]$

$\mathrm{X}$ - suspender a execução, no todo ou em parte, de lei declarada inconstitucional por decisão definitiva do Supremo Tribunal Federal; (BRASIL, 1988).

Para o STF, houve mutação constitucional, passando o texto do referido inciso $\mathrm{X}$ do art. 52 da CRFB/88 ter o seguinte significado, conforme palavras do Ministro Eros Grau, em voto vista da Reclamação 4.335-5/AC: "compete privativamente ao Senado Federal dar publicidade à suspensão da execução, operada pelo Supremo Tribunal Federal, de lei declarada inconstitucional, no todo ou em parte, por decisão definitiva do Supremo" (STF, Pleno, Recl. 4.335-5/SC, Rel. Min. Gilmar Mendes, Voto Vista, proferido em 19-4-2007). (BRASIL, 2007).

Dessa forma, não caberia ao Senado suspender a execução, como está no texto da Constituição, mas apenas dar publicidade à suspensão da execução, esta já determinada pelo STF, cuja decisão já teria força normativa bastante para suspender a execução de lei declarada inconstitucional.

Assim, teria ocorrido a mutação constitucional, pois houve alteração da Constituição, sem que o seu texto tenha sido alterado formalmente, haja vista que, para Mendes, "A suspensão da execução pelo Senado Federal do ato declarado inconstitucional pelo Supremo Tribunal Federal foi a forma definida pelo constituinte para emprestar eficácia erga omnes às decisões definitivas sobre inconstitucionalidade". (STF, Pleno, Recl. 4.335-5/AC, Rel. Min. Gilmar Mendes, voto, p. 4). (BRASIL, 2007).

Em sentido contrário, Bulos defende que não houve mutação constitucional, pois neste fenômeno não há substitui- 
ção do texto por outro, como defendem os Ministros Gilmar Mendes e Eros Grau na Recl. 4.335-5/AC ao afirmarem que "[...] na mutação constitucional não apenas a norma é nova, mas o próprio texto normativo é substituído por outro". (BULOS, 2014, p. 232).

Ainda segundo o referido autor, ao defender tal tese, os ministros do STF acabam por culminar em exercício de legiferação positiva, inadmitida pelo próprio STF. Assim, teria ocorrido, na verdade, outro fenômeno, chamado de manipulação inconstitucional. (BULOS, 2014, p. 232).

E continua:

Na realidade, o que aconteceu com o art. 52, X, da Constituição de 1998 foi a sua inadequabilidade em face das transformações do fato social cambiante, acarretando-lhe desuso, e não mutação constitucional. Desuso é a não aplicação ou desobediência a uma norma, sem que haja criação de outa que se lhe oponha, em virtude de sua inadequabilidade social. (BULOS, 2014, p. 232).

Por fim, argumenta que:

$\mathrm{O}$ art. 52, X, do Texto de 1988, por exemplo, não sofreu qualquer mutação constitucional, embora esteja passando por um lento e gradual processo de desuso, haja vista a sua inadequabilidade social, algo que, a nosso sentir não constitui uma verdadeira reforma da Constituição sem expressa mudança do texto. (BULOS, p. 234).

Também para Sarmento a mutação constitucional "[...] jamais poderá significar ruptura com o sistema plasmado pelo constituinte, ou desrespeito ao sentido mínimo das cláusulas pétreas [...]", concluindo que se tal fato ocorrer, "[...] a hipótese já não será de mutação, mas de violação à ordem constitucional." (SARMENTO, 2017, p.359).

Dessa forma, é possível a interpretação inconstitucional, por meio da mutação inconstitucional, que é a violação da carta magna, que podem ocorrer tanto pelo STF, se interpretar 
contra legem algum dispositivo constitucional, pois a interpretação deve encontrar amparo no texto, não podendo a interpretação se dar de forma deformadora dos princípios fundamentais que embasam o documento, bem como pode ocorrer por meio da inércia legislativa, "[...] no momento em que o legislador fica incumbido de fazer lei ou ato normativo para regular a constituição e não o faz, transgride a própria manifestação constituinte originária”. (BULOS, 2014, p. 439).

Por fim, há a interpretação inconstitucional por meio da manipulação inconstitucional das normas constitucionais, que é o desrespeito a tais normas, bem como um "perigoso veículo de mutação inconstitucional, verificando-se em diversas situações, impossíveis de serem enumeradas exaustivamente". (BULOS, 2014, p. 441).

A seguir, exemplifica o autor algumas possibilidades de manipulação inconstitucional:

a) "conferir às palavras escritas nas constituições sentidos totalmente ilógicos e absurdos"; b) "interpretar um dispositivo constitucional como se não existissem outros;" (exemplo: HC 96.301/SP, de relatoria da Min. Ellen Gracie, de 02/10/2008, em que o STF impediu tal ocorrência); c) "legitimar competências inconstitucionais" (exemplo: RE 496.718/RS, de relatoria do Min. Menezes Direito, de 12/08/2008); e d) "criar exceções não previstas constitucionalmente" (exemplo: MS 26.700/RO, de relatoria do Min. Ricardo Lewandowski, de 30/05/2008). (BULOS, 2014, p. 441-442).

Assim, pode-se concluir que é possível a interpretação inconstitucional, precipuamente por meio da mutação inconstitucional, mas que tal fenômeno não é exclusividade da jurisdição constitucional, podendo ocorrer também por meio da omissão legislativa.

\section{CONCLUSÃO}

Conforme já adiantado na introdução, o presente trabalho 
não tem como objetivo tratar de forma aprofundada das questões nele tratadas, por ser extremamente complexo e demandar muito espaço e também extensa pesquisa. Ainda que fosse essa a pretensão, não seria possível esgotar a matéria, pois é algo que está sempre em evolução e mudando de acordo com as transformações sociais e jurídicas que ocorrem constantemente, bem como por ser, como visto, a interpretação constitucional, por mais que se utilizem técnicas e métodos interpretativos, é tarefa com grande subjetivismo, eis que difusa, podendo (senão devendo) ser atribuída a todo aquele que está sob a égide da Constituição.

Ademais, o que se buscou no trabalho foi mostrar a importância da interpretação constitucional, da legitimidade democrática e da dificuldade contramajoritária do poder judiciário, bem como da possibilidade de haver interpretação inconstitucional.

Apesar de poderem ser estudadas e analisadas de maneira individualizada, as matérias não são estanques, não devendo (nem podendo) ser isoladas umas das outras, pois estão intimamente interligadas.

Portanto, conclui-se que a interpretação constitucional é dever de todos os poderes, que dela decorrem, sob pena de desrespeitarem a Lei Fundamental. A interpretação da Constituição, assim, não é exclusividade do Poder Judiciário, que tem legitimidade democrática para tanto, cabendo ao Supremo Tribunal Federal a guarda da Constituição.

Com relação à última palavra na interpretação constitucional, é possível e saudável em se tratando de controle abstrato da constitucionalidade de atos normativos, pois é o meio pelo qual se obtém a segurança jurídica e a pacificação social.

No entanto, existem mecanismos de reação a dada interpretação, podendo ser por meio de emendas constitucionais, edição de leis análogas às já declaradas inconstitucionais, bem como por meio da mobilização para que os novos mi- 
nistros que venham a ser nomeados tenham visão diferente sobre temas debatidos.

Toda sociedade deve participar do debate sobre temas que tenham maior repercussão, pois é ela a destinatária do texto constitucional, que deve ser interpretado sempre de modo que lhe seja favorável.

Por fim, constatou-se que pode haver a interpretação inconstitucional, precipuamente por meio da mutação inconstitucional, e que esta se dá tanto por meio do controle difuso de constitucionalidade, quanto pela inércia legislativa em regular matéria constitucional.

\section{REFERÊNCIAS}

BARROSO, Luís Roberto. Curso de direito constitucional contemporâneo: os fundamentos constitucionais e a Constituição do novo modelo. São Paulo: Saraiva, 2009a.

BASTOS, Celso Ribeiro. Curso de direito constitucional. 18. ed. São Paulo: Saraiva, 1997.

BRASIL. Constituição da República Federativa do Brasil de 1988. Disponível em: $<$ http://www.planalto.gov.br/ccivil_03/constituicao/constituicaocompilado.htm>. Acesso em: 10 out. 2016.

BULOS, UadiLammêgo. Curso de direito constitucional. 8. ed. rev. e atual. São Paulo: Saraiva. 2014.

CANOTILHO, J.J. Gomes. Direito constitucional e teoria da constituição. 7. ed. 15. reimpr. 2003.

HÄBERLE, Peter. Hermenêutica Constitucional - A Sociedade Aberta dos Intérpretes da Constituição: Contribuição para Interpretação Pluralista e "Procedimental" da Constituição. In:

Revista da Defensoria Pública da União - DPU No 60 - Nov-Dez/2014. - Assunto Especial - textos Clássicos. p. 25/50. Disponível em: $<$ https://www.portaldeperiodicos. idp.edu.br/direitopublico/article/view/2353/1204> Acesso em: 14 jun. 2017.

MENDES, Gilmar Ferreira; BRANCO, Paulo Gustavo Gonet. Curso de direito constitucional. 12. ed. rev. e atual. São Paulo: Saraiva Jur. 2017 (Série IDP).

MORAES, Alexandre de. Direito constitucional. 28. ed. São Paulo: Atlas, 2012.

OLIVEIRA, James Eduardo. Constituição Federal anotada e comentada: doutrina e jurisprudência. Rio de Janeiro: Forense, 2013.

PAULO, Vicente; ALEXANDRINO, Marcelo. Direito constitucional descomplicado. 14. ed. Rio de Janeiro: Forense; São Paulo: MÉTODO: 2015. 
SARMENTO, Daniel; SOUZA NETO, Cláudio Pereira de. Direito constitucional: teoria, história e métodos de trabalho. 2. ed. 3. reimpr. Belo Horizonte: Fórum, 2017.

SILVA, José Afonso da.Curso de direito constitucional positivo. 32. ed. rev. e atual. São Paulo: Malheiros Editores. 2008.

STRECK, Lenio Luiz; MORAIS, Jose Luiz Bolzan de. Ciência politica e teoria geral do Estado. 3. ed. Porto Alegre: Livraria do Advogado, 2003.

THEODORO JUNIOR, Humberto. O sistema jurídico positivo e o impacto da era das reformas legislativas. In: Estudos de direito constitucional. Belo Horizonte: Del Rey, 2009.

Artigo recebido em: 16/06/2017

Artigo aprovado em: 02/10/2017 